\title{
MỘT SỐ KẾT QUẢ ĐIỀU TRA, NGHIÊN CÚ̉U VỀ NGUỒN TÀI NGUYÊN \\ CÂY THUỐC CỦA ĐỒNG BÀO DÂN TỘC CAO LAN KHAI THÁC Ở KHU RÙ̀NG ĐẶC DỤNG NA HANG, TỈNH TUYÊN QUANG
}

\section{Some investtigative and scientific research reasults on medicinal plant resources of Cao Lan ethnic in the Na Hang nature reserve, Tuyen Quang province}

ThS. Nguyễn Thị Hải*; ThS. Đoàn Thị Phương Lý* TS. Nguyễn Thế Cường ***; PGS.TS. Trần Huy Thái** TS. Nguyễn Anh Tuấn ${ }^{* * *}$

\section{TÓM TẮT}

Khu Bảo tồn thiên nhiên Na Hang là một trong nhũng nơi có nguồn tài nguyên cây thuốc đa dạng và phong phú. Hiện biết có 275 loài cây thuốc, thuộc 4 ngành, 96 ho, 204 chi của thục vật có mạch, đã được ghi lại trong các cuộc điều tra thực địa. Trong số đó, có 204 loài, thuộc 3 ngành, 85 họ, 168 chi của thục vật có mạch được sử dụng bởi Cao Lan dân tộc; đã 05 loài được liệt kê trong Sách Đỏ Việt Nam và Danh lục Đỏ cây thuốc Việt Nam.

Trong số 85 họ, có 11 ho có số loài nhiều nhất là ho Rubiaceae, Euphorbiaceae, Zingberaceae, Araceae, Vitaceae, Acanthaceae, Verbenaceae, Myrsinaceae, Moraceae, Menispermaceae và Convallariaceae.

Bốn loại phổ biến của cây thuốc là cây thân thảo (41,63\%), cây bụi (22.01\%), cây thân gố $(16,75 \%)$ và leo núi (17.70\%). Các bộ phận được sử dụng nhiều nhất thân, lá, rễ và toàn cây. Các nguồn tài nguyên cây thuốc ở khu bảo tồn thiên nhiên Na Hang có giá trị kinh tế quan trọng và một tiềm năng để phát triển dược phẩm mới và các sản phẩm tụ nhiên khác.

Tù khóa: cây thuốc, Sách Đỏ, Danh lục đỏ của cây thuốc, Cao Lan, Na Hang, Tuyên Quang.

\section{ABSTRACT}

Na Hang Natural Reserve is one of areas where has diverse and rich natural resource of traditional medicine. There are 275 kinds of medicinal plants and belong to 4 branches, 96 offshoots, and 204 limbs of vessel plant which has been written in field investigations. In those medicinal plants, there are 204 species belong to 3 branches, 85 offshoots, 168 limbs of vessel plant which are currently used by Cao Lan ethnic group, and there are also 5 species of those are listed in Red Book Vietnam and in Red Booklist of Medicinal Plants Vietnam.

In 85 offshoots, there are11 offshoots which have the most number of species, these are: Rubiaceae, Euphorbiaceae, Zingberaceae, Araceae, Vitaceae, Acanthaceae, Verbenaceae, Myrsinaceae, Moraceae, Menispermaceae và Convallariaceae.

Four popular plants of medicinal plant are Than thao plant $(41,63 \%)$, bush $(22,01 \%)$, wooden plant $(16,75 \%)$, and mountain - climb plant (17,70\%). Parts are most used including trunks, leaves, roots.

Natural resource of traditional medicine in Na Hang Natural Reserve has important economic value and is a potential to develop new medicine and other natural products.

Keywords: Medicinal plant, Red Data Book, Red List of Medicinal plants, Cao Lan, Na Hang, Tuyen Quang.

\footnotetext{
* Đại học Tân Trào

*** Viện Sinh thái và Tài nguyên Sinh vật, Viện Hàn lâm KH \& CN Việt Nam

*** Nhà xuất bản Khoa học tự nhiên và Công nghệ, Viện Hàn lâm KH \& CN Việt Nam
} 


\section{Mở đầu}

Rừng đặc dụng $\mathrm{Na}$ Hang (trước đây là Khu bảo tồn thiên nhiên Tát kẻ - Bản Bung huyện Na Hang) được thành lập theo Quyết định 274/UB-QĐ ngày 9 tháng 5 năm 1994 của Uỷ ban nhân dân tỉnh Tuyên Quang. Nằm trên địa bàn các xã Khâu Tinh, Côn Lôn, Sơn Phú, Thanh Tương của huyện $\mathrm{Na}$ Hang, tỉnh Tuyên Quang. Rừng đặc dụng Na Hang có diện tích tự nhiên khoảng 22.401,5 ha, trong đó diện tích khu vực có địa hình dưới 300 m chiếm khoảng 30\%, 300-800 m chiếm 60\%, trên $900 \mathrm{~m}$ chiếm $10 \%$. Mùa đông nhiệt độ trung bình $15-20^{\circ} \mathrm{C}$, mùa hè nhiệt độ lên đến $30^{\circ} \mathrm{C}$ hoặc có thể hơn. Hệ thống sông ngòi chỉ ở mức trung bình, có hai con sông lớn chảy qua là sông Gâm (phía Tây Tát Kẻ) và sông Năng (phía đông $\mathrm{Na} H a n g$ ). Hiện nay, nguồn nước từ rừng đặc dụng $\mathrm{Na}$ Hang được phân phối, điều hòa bởi hệ thống lòng hồ và đập thủy điện Na Hang.

Theo Nguyễn Nghĩa Thìn và Đặng Quyết Chiến (2006), hệ thực vật tại Khu bảo tồn thiên nhiên (BTTN) Na Hang có 1.162 loài thực vật, thuộc 604 chi, 159 họ của 4 ngành thực vật bậc cao có mạch. Trong đó ngành Hạt kín (Angiospermae) có 1.083 loài, 570 chi, 135 họ; ngành Hạt trần (Gymnospermae) có 11 loài, 8 chi, 5 họ; ngành Dương xỉ (Polypodiophyta) có 63 loài, 34 chi, 17 họ; nhành Thông đất (Lycopodiophyta) có 5 loài, 2 chi, 2 họ. Trong số 1162 loài thực vật được ghi nhận tại Khu BTTN Na Hang, có 558 loài thực vật được ghi nhận có giá trị làm thuốc [14].

Việc nghiên cứu hiện trạng của nguồn tài nguyên cây thuốc có vị trí rất quan trọng trong nguồn tài nguyên sinh vật ở rừng đặc dụng $\mathrm{Na}$ Hang. Đây là những tư liệu góp phần làm cơ sở khoa học cho việc xây dựng chiến lược quản lý, bảo tồn và phát triển bền vững tính đa dạng sinh học của Na Hang, tỉnh Tuyên Quang trong tương lai.

Theo số liệu cuối năm 2013, người Cao Lan ở Việt Nam có khoảng 200.000 người, có mặt tại 58 trên tổng số 63 tỉnh, thành phố. Người Cao Lan cư trú tập trung nhiều nhất tại tỉnh Tuyên Quang với 66.805 người, chiếm gần $40 \%$ tổng số người Cao Lan tại Việt Nam. Trong tỉnh Tuyên Quang, người Cao Lan sống tập trung đông nhất ở huyện Sơn Dương, Yên Sơn, Hàm Yên và là dân tộc thiểu số đông thứ 3 trong tỉnh, chỉ sau dân tộc Tày, Dao.

Tỉnh Tuyên Quang do có địa hình đồi núi phức tạp nên việc chăm sóc sức khỏe, khám và chữa bệnh cho người dân còn rất hạn chế và khó khăn. Mặt khác, với cuộc sống trong rừng - nơi có nhiều loài cây cung cấp nguồn dược liệu phong phú và đa dạng, người dân Cao Lan đã tự tìm hiểu và tìm ra được rất nhiều loài cây rừng có tác dụng chữa được nhiều bệnh. Những tri thức và kinh nghiệm sử dụng những loài cây để chữa bệnh đã được người dân địa phương gìn giữ và lưu truyền lại qua nhiều đời, thế hệ sau.

Rừng đặc dụng $\mathrm{Na}$ Hang, tỉnh Tuyên Quang có nguồn tài nguyên cây thuốc đa dạng và phong phú. Các ông Lang, bà Mế người dân tộc Cao Lan từ các huyện Sơn Dương, Yên Sơn và Hàm Yên lên Chiêm Hóa và Na Hang hái và thu mua cây thuốc.

Cho đến nay, một phần nhỏ người dân, đặc biệt là các ông Lang, bà Mế người dân tộc Cao Lan ở đây đã đưa một số loài cây thuốc về trồng trong vườn nhà khi nguồn tài nguyên cây thuốc dần khan hiếm và được bảo vệ nghiêm ngặt. Tuy nhiên, với số lượng nhỏ và một số loài không thể gây trồng được nên họ vẫn khai thác nguồn tài nguyên cây thuốc trong rừng để bán, chữa bệnh cho người dân trong vùng và người dân từ các tỉnh khác đến.

Công trình này nhằm hệ thống, tìm hiểu giá trị sử dụng nguồn tài nguyên cây thuốc được sử dụng bởi người dân tộc Cao Lan ở các huyện khai thác tại Khu rừng đặc dụng $\mathrm{Na} H a n g$, tỉnh Tuyên 
Quang, đồng thời bước đầu đề xuất một số giải pháp phát triển cho cộng đồng dân cư địa phương trong vùng đệm của $\mathrm{Na}$ Hang.

\section{Vật liệu và phương pháp nghiên cứu}

Vật liệu nghiên cứu là toàn bộ nguồn tài nguyên cây thuốc được sử dụng bởi người dân tộc Cao Lan đã khai thác tại các xã Thanh Tương, Sơn Phú và Khau Tinh thuộc huyện Na Hang, tỉnh Tuyên Quang (bảng 1).

\begin{tabular}{|c|c|c|c|c|}
\hline STT & Địa điểm & $\begin{array}{l}\text { Thò̀i gian } \\
\text { nghiên cứu }\end{array}$ & Tọa độ & $\begin{array}{l}\text { Độ cao so với } \\
\text { mặt nước biển }\end{array}$ \\
\hline 1 & $\begin{array}{l}\text { Bản Khuổi Bốc, } \\
\text { Thanh Tương, Na } \\
\text { Hang }\end{array}$ & 23-24.v.2014 & $\begin{array}{l}\text { N: } 22.17 ' 33,4 " ; \\
\text { E: } 105.24 ' 38,1 "\end{array}$ & $120 \mathrm{~m}$ \\
\hline 2 & $\begin{array}{l}\text { Bản Bung, Thanh } \\
\text { Tương, Na Hang }\end{array}$ & $\begin{array}{l}\text { 20-22.v.2014 } \\
\text { 10-12.x.2014 } \\
\text { 10-15.iv.2015 }\end{array}$ & $\begin{array}{l}\text { N: } 22.15^{\prime} 44,2^{\prime \prime} \\
\text { E: } 105.25^{\prime} 48,5^{\prime \prime}\end{array}$ & $349 m-432 m$ \\
\hline 3 & $\begin{array}{l}\text { Bản Chủ, Sơn Phú, } \\
\text { Na Hang }\end{array}$ & $13-15 . x .2014$ & $\begin{array}{l}\text { N: } 22.20^{\prime} 54,1^{\prime \prime} ; \\
\text { E: } 105.25^{\prime} 45,5^{\prime \prime}\end{array}$ & $259 \mathrm{~m}$ \\
\hline 4 & $\begin{array}{l}\text { Bản Thác Mơ, Sơn } \\
\text { Phú, Na Hang }\end{array}$ & $\begin{array}{l}25-26 . v .2014 \\
16-18 . x .2014 \\
\end{array}$ & $\begin{array}{l}\text { N: } 22.21^{\prime} 08,2^{\prime \prime} \\
\text { E: } 105.25^{\prime} 11,7^{\prime \prime}\end{array}$ & $194 m-418 m$ \\
\hline 5 & $\begin{array}{l}\text { Bản Nà Tang, Khau } \\
\text { Tinh, Na Hang }\end{array}$ & 19-22.x.2014 & $\begin{array}{l}\text { N: } 22.27 ' 52,2^{\prime \prime} ; \\
\text { E: } 105.26 ' 19,4^{\prime \prime}\end{array}$ & $774 m-891 m$ \\
\hline
\end{tabular}

Bảng 1. Địa điểm và thời gian thu mẫu tại Khu rùng đặc dụng Na Hang, tỉnh Tuyên Quang

Trong quá trình nghiên cứu, chúng tôi đã sử dụng các phương pháp nghiên cứu sau:

- Điều tra nguồn tài nguyên theo tuyến và ô tiêu chuẩn nhằm thu mẫu cho việc giám định tên khoa học và phân tích hóa học.

- Phân loại thực vật: Dựa vào phương pháp so sánh đặc điểm hình thái, phương pháp chuyên gia và sử dụng các tài liệu chuyên ngành.

- Phương pháp kế thừa tài liệu: Tìm hiểu, thu thập, các tài liệu đã nghiên cứu có liên quan.

- Điều tra tri thức bản địa, những kinh nghiệm của các ông lang, bà mế người dân tộc Cao Lan và thu mẫu tiêu bản tại thực địa.

- Mẫu vật được lưu giữ tại Phòng Thực vật, Viện Sinh thái và Tài nguyên Sinh vật, Viện Hàn lâm KH \& CN Việt Nam.

\section{Kết quả và thảo luận}

1. Thành phần cây thuốc tại khu rừng đặc dụng $\mathrm{Na} H a n g$, tỉnh Tuyên Quang

\begin{tabular}{|c|l|c|c|c|c|c|c|}
\hline \multirow{2}{*}{ STT Ngành } & \multicolumn{2}{|c|}{ Ho } & \multicolumn{2}{c|}{ Chi } & \multicolumn{2}{c|}{ Loài } \\
\cline { 3 - 8 } & & $\begin{array}{c}\text { Số } \\
\text { lượng }\end{array}$ & $\begin{array}{c}\text { Tỷ lệ } \\
\%\end{array}$ & $\begin{array}{c}\text { Số } \\
\text { lượng }\end{array}$ & $\begin{array}{c}\text { Tỷ lệ } \\
\%\end{array}$ & $\begin{array}{c}\text { Số } \\
\text { lượng }\end{array}$ & $\begin{array}{c}\text { Tỷ lệ } \\
\%\end{array}$ \\
\hline 1 & Lycopodiophyta - Thông đất & 1 & 1,04 & 1 & 0,49 & 2 & 0,73 \\
\hline 2 & Polypodiophyta - Dương xî̀n & 7 & 7,29 & 7 & 3,43 & 8 & 2,91 \\
\hline 3 & Pinophyta - Thông & 1 & 1,04 & 1 & 0,49 & 1 & 0,36 \\
\hline 4 & Magnoliophyta - Mộc lan & 87 & 90,63 & 195 & 95,59 & 264 & 96,00 \\
\hline \multirow{2}{*}{} & Magnoliopsida - Lớp Mộc lan & 71 & 73,96 & 160 & 78,43 & 220 & 80,00 \\
\cline { 2 - 9 } & Liliopsida - Lớp Hành & 16 & 16,67 & 35 & 17,16 & 44 & 16,00 \\
\hline & Tổng & $\mathbf{9 6}$ & & $\mathbf{2 0 4}$ & & $\mathbf{2 7 5}$ & \\
\hline
\end{tabular}

Bảng 2. Thành phần loài cây thuốc tại rùng đặc dụng Na Hang 
Từ kết quả điều tra trong năm 2014 và 2015, chúng tôi đã tập hợp, thu mẫu tiêu bản tại thực địa; xác định tên khoa học và thống kê được 275 loài cây thuốc thuộc 204 chi và 96 họ thực vật bậc cao có mạch được người dân sử dụng để làm thuốc trị bệnh (bảng 2).

Bảng 2 cho thấy, thành phần loài cây thuốc chủ yếu thuộc ngành Mộc Lan (Magnoliophyta), chiếm $90,63 \%$ tổng số họ; $95,59 \%$ tổng số chi và 96,00\% tổng loài. Các ngành khác có số lượng họ, chi và loài được sử dụng làm thuốc với tỷ lệ thấp. Trong ngành Mộc lan, lớp Mộc lan chiếm $73,96 \%$ tổng số họ, $78,43 \%$ tổng số chi và $80,00 \%$ tổng số loài; lớp Hành chiếm $16,67 \%$ tổng số họ, $17,16 \%$ tổng số chi và $16,00 \%$ tổng số loài.

Trong số 96 họ, có 10 họ có số loài nhiều nhất là họ Cà phê - Rubiaceae (20 loài); họ Gai Urticaceae (19 loài); họ Ô rô - Acanthaceae, Thầu dầu - Euphorbiaceae, Ráy - Araceae và họ Gừng - Zingberaceae (9 loài); họ Cỏ roi ngựa - Verbenaceae (8 loài); họ Dâu tằm - Moraceae, họ Cúc Asteraceae và Mạch môn đông - Convallariaceae (7 loài).

Trong số 204 chi, có 4 chi có số lượng loài được sử dụng làm thuốc nhiều nhất là chi Ficus (6 loài), Piper (5 loài), Elastostema (5 loài) và Clerodendrum (5 loài).

\section{Thành phần cây thuốc được người dân tộc Cao Lan sử dụng tại rùng đặc dụng Na Hang}

\begin{tabular}{|c|l|c|c|c|c|c|c|}
\hline \multirow{2}{*}{ STT } & \multicolumn{2}{|c|}{ Ngành } & \multicolumn{2}{|c|}{ Ho } & \multicolumn{2}{c|}{ Chi } & \multicolumn{2}{c|}{ Loài } \\
\cline { 3 - 8 } & & $\begin{array}{c}\text { Số } \\
\text { lượng }\end{array}$ & $\begin{array}{c}\text { Tỷ lệ } \\
\%\end{array}$ & $\begin{array}{c}\text { Số } \\
\text { lượng }\end{array}$ & $\begin{array}{c}\text { Tỷ lệ } \\
\%\end{array}$ & $\begin{array}{c}\text { Số } \\
\text { lượng }\end{array}$ & Tỷ lệ \% \\
\hline 1 & Lycopodiophyta - Thông đất & 0 & 0 & 0 & 0 & 0 & 0 \\
\hline 2 & Polypodiophyta - Dương xỉ & 5 & 5,88 & 5 & 2,98 & 5 & 2,39 \\
\hline 3 & Pinophyta - Thông & 1 & 1,18 & 1 & 0,60 & 1 & 0,48 \\
\hline 4 & Magnoliophyta - Mộc lan & 79 & 92,94 & 162 & 96,43 & 203 & 97,13 \\
\hline \multirow{2}{*}{$\begin{array}{c}\text { Magnoliopsida - Lớp Mộc } \\
\text { lan }\end{array}$} & 62 & 72,94 & 129 & 76,79 & 163 & 77,99 \\
\cline { 2 - 8 } & Liliopsida - Lớp Hành & 17 & 20 & 33 & 19,64 & 40 & 19,14 \\
\hline & Tổng & $\mathbf{8 5}$ & & $\mathbf{1 6 8}$ & & $\mathbf{2 0 9}$ & \\
\hline
\end{tabular}

Bảng 3. Thành phần loài cây thuốc tại rùng đặc dụng Na Hang

Bảng 3 cho thấy, thành phần loài cây thuốc được người dân tộc Cao Lan sử dụng chủ yếu thuộc ngành Mộc Lan (Magnoliophyta), chiếm 92,94\% tổng số họ; 96,43\% tổng số chi và 97,13\% tổng số loài. Các ngành khác có số lượng họ, chi và loài được sử dụng làm thuốc với tỷ lệ thấp.

Trong ngành Mộc lan, lớp Mộc lan chiếm 72,94\% tổng số họ, 76,79\% tổng số chi và 77,99\% tổng số loài; lớp Hành chiếm 20,00\% tổng số họ, 19,64\% tổng số chi và 19,14\% tổng số loài.

Trong số 85 họ, có 11 họ có số loài nhiều nhất là họ Cà phê Rubiaceae (11 loài); Thầu dầu Euphorbiaceae và họ Gừng - Zingberaceae (9 loài); Ráy - Araceae và họ Nho - Vitaceae (8 loài); họ Ô rô Acanthaceae (7 loài); họ Cỏ roi ngựa - Verbenaceae và họ Cơm nguội - Myrsinaceae (6 loài); họ Dâu tằm - Moraceae, họ Tiết dê - Menispermaceae và Mạch môn đông - Convallariaceae (5 loài).

Trong số 168 chi, có 4 chi có số lượng loài được sử dụng làm thuốc nhiều nhất là chi Piper (5 loài), Ficus (4 loài), Elastostema (5 loài) và Clerodendrum (5 loài). 
So sánh thành phần loài cây thuốc mà người dân tộc Cao Lan sử dụng với thành phần loài toàn khu rừng đặc dụng $\mathrm{Na}$ Hang, tỉnh Tuyên Quang, chúng tôi thu được kết quả sau (bảng 4):

\begin{tabular}{|c|c|c|c|c|}
\hline \multirow[b]{2}{*}{ STT } & \multirow[b]{2}{*}{ Ngành } & \multirow[b]{2}{*}{ Na Hang } & \multicolumn{2}{|c|}{ Cao Lan } \\
\hline & & & $\begin{array}{c}\text { Số lượng } \\
\text { loài }\end{array}$ & $\begin{array}{c}\text { Tỷ lệ \% (thành } \\
\text { phần cây thuốc } \\
\text { Na Hang) }\end{array}$ \\
\hline 1 & Lycopodiophyta - Thông đất & 2 & 0 & 0 \\
\hline 2 & Polypodiophyta - Dương xỉ & 8 & 5 & 1,82 \\
\hline 3 & Pinophyta - Thông & 1 & 1 & 0,36 \\
\hline 4 & Magnoliophyta - Mộc lan & 264 & 203 & 73,82 \\
\hline & Tổng & 275 & 209 & 76,00 \\
\hline
\end{tabular}

Bảng 4. So sánh thành phần loài cây thuốc nguời dân tộc Cao Lan sủ dụng với thành phần cây thuốc tại rùng đặc dụng Na Hang

Từ kết quả ở bảng 4 cho thấy, người dân tộc Cao Lan sử dụng cây thuốc rất đa dạng và phong phú, chiếm $76 \%$ tổng số loài cây thuốc toàn khu vực rừng đặc dụng $\mathrm{Na} H a n g$, tỉnh Tuyên Quang.

\section{Giá trị về nguồn gien quý hiếm ${ }^{1}$}

\begin{tabular}{|c|l|l|l|l|}
\hline STT & \multicolumn{1}{|c|}{ Tên khoa học } & \multicolumn{1}{c|}{ Tên thông dụng } & SĐVN2007 & \multicolumn{1}{c|}{ DLĐ2006 } \\
\hline 1. & $\begin{array}{l}\text { Balanophora laxiflora } \\
\text { Hémley } \\
\text { Balanophoraceae }\end{array}$ & $\begin{array}{l}\text { Dương đài (Tỏa } \\
\text { dương) } \\
\text { Pi đin (Tày) }\end{array}$ & EN B1+2b,c,e & $\begin{array}{l}\text { VU } \\
\text { A1c,d }\end{array}$ \\
\hline 2. & $\begin{array}{l}\text { Podophyllum tonkinensis } \\
\text { Gagnep. } \\
\text { Berberidaceae }\end{array}$ & $\begin{array}{l}\text { Bát giác liên } \\
\text { Bâu chất cooc (Tày) }\end{array}$ & EN A1a,c,d & $\begin{array}{l}\text { EN } \\
\text { A1 c,d }\end{array}$ \\
\hline 3. & $\begin{array}{l}\text { Gynostemma pentaphyllum } \\
\text { (Thunb.) Makino } \\
\text { Cucurbitaceae }\end{array}$ & $\begin{array}{l}\text { Giảo cố lam } \\
\text { Pyắc dạ (Tày); } \\
\text { Lày im (Dao) }\end{array}$ & EN A1a,c,d & $\begin{array}{l}\text { EN } \\
\text { A1a,c,d }\end{array}$ \\
\hline 4. & $\begin{array}{l}\text { Ardisia silvestris Pitard } \\
\text { Myrsinaceae }\end{array}$ & Lá khôi & $\begin{array}{l}\text { VU } \\
\text { Ala,c,d+2d }\end{array}$ & $\begin{array}{l}\text { VU } \\
\text { A1c,d }\end{array}$ \\
\hline 5. & $\begin{array}{l}\text { Embelia parviflora Wall. ex } \\
\text { A. DC. } \\
\text { Myrsinaceae }\end{array}$ & Rè đẹt & $\begin{array}{l}\text { VU } \\
\text { A1a,c,d+2d }\end{array}$ & A1c,d \\
\hline
\end{tabular}

Bảng 5. Danh sách các loài cây thuốc quý hiếm tại rùng đặc dụng Na Hang, tỉnh Tuyên Quang

Trong số 209 loài cây thuốc đã điều tra được, có 5 loài được ghi trong Sách Đỏ Việt Nam (2007) [2] và Danh Lục Đỏ cây thuốc Việt Nam (2006) [11, 12] (bảng 5). Đây là nguồn gien quý hiếm, cần có biện pháp bảo tồn nghiêm ngặt.

Trong Danh lục đỏ cây thuốc Việt Nam 2006, có 02 loài được xếp ở cấp độ EN (Nguy cấp) và 03 loài được xếp ở cấp độ VU (Sẽ nguy cấp) (bảng 5). Trong Sách Đỏ Việt Nam 2007, có 03 loài được xếp ở cấp độ $\mathrm{EN}$ (Nguy cấp) và 02 loài được xếp ở cấp độ VU (Sẽ nguy cấp).

\footnotetext{
${ }^{1}$ Ghi chú: SĐVN2007. Sách Đỏ Việt Nam 2007; DLĐ2006. Danh luc Đỏ cây thuốc Việt Nam 2006; SĐ. Sách Đỏ Việt Nam 2007; VU. sẽ nguy cấp; EN. nguy cấp; CR. Rất nguy cấp
} 
4. Dạng sống của các loài cây thuốc được người dân tộc Cao Lan sử dụng

\begin{tabular}{|c|l|c|c|}
\hline STT & \multicolumn{1}{|c|}{ Dạng sống } & Số loài & Tỷ lệ \% \\
\hline 1. & Cây thân gỗ & 35 & 16,75 \\
\hline 2. & Cây bụi & 46 & 22,01 \\
\hline 3. & Cây thân leo & 37 & 17,70 \\
\hline 4. & Cây thân thảo & 87 & 41,63 \\
\hline 5. & Cây bì sinh & 3 & 1,44 \\
\hline 6. & Cây kí sinh & 1 & 0,48 \\
\hline & Tổng & $\mathbf{2 0 9}$ & 100 \\
\hline
\end{tabular}

Bảng 6. Dạng sống của các loài cây thuốc được người dân tộc Cao Lan sủ dụng

Hệ thực vật bậc cao có mạch ở khu rừng đặc dụng $\mathrm{Na} H a n g$, tỉnh Tuyên Quang có dạng sống khá phong phú, còn dạng sống chủ yếu của các loài cây thuốc được người dân tộc Cao Lan sử dụng chủ yếu là cây thân thảo (chiếm $41,63 \%$ so với tổng số loài) và cây bụi (chiếm $22,01 \%$ ); cây thân gỗ và cây thân leo được sử dụng ít hơn (tỷ lệ lần lượt là $16,75 \%$ và $17,70 \%$ ); còn lại là cây bì sinh và cây kí sinh chiếm tỷ lệ rất thấp. Điều này phản ánh đúng về phương thức sử dụng các cây thuốc của các dân tộc nói chung ở Việt $\mathrm{Nam}$, cây thân thảo và cây bụi vẫn là những dạng sống được sử dụng làm thuốc nhiều nhất.

5. Bộ phận được sử dụng làm thuốc

\begin{tabular}{|c|l|c|c|}
\hline STT & \multicolumn{1}{|c|}{ Bộ phận } & Số loài & Tỷ lệ \% \\
\hline 1 & Toàn cây & 37 & 15,29 \\
\hline 2 & Thân & 73 & 30,17 \\
\hline 3 & Lá & 61 & 25,21 \\
\hline 4 & Rễ & 36 & 14,88 \\
\hline 5 & Củ & 8 & 3,31 \\
\hline 6 & Quả & 8 & 3,31 \\
\hline 7 & Hạt & 8 & 3,31 \\
\hline 8 & Lông & 1 & 0,41 \\
\hline 9 & Vỏ thân & 5 & 2,07 \\
\hline 10 & Vỏ rễ & 5 & 2,07 \\
\hline & Tổng & $\mathbf{2 4 2}$ & $\mathbf{1 0 0}$ \\
\hline
\end{tabular}

Bảng 7. Danh mục các bộ phận của cây được sủ dụng làm thuốc của người dân tộc Cao Lan

Có 10 bộ phận đã được thống kê trong phương thức sử dụng cây thuốc của đồng bào dân tộc Cao Lan ở rừng đặc dụng $\mathrm{Na} H a n g$, tỉnh Tuyên Quang (bảng 7). Trong đó, các bộ phận được sử 
dụng nhiều nhất là Thân (chiếm 30,17\%), Lá $(25,21 \%$ ) và Rễ $(14,88 \%)$; số loài cây có tất cả các bộ phận được sử dụng làm thuốc chiếm $15,29 \%$, còn lại là các bộ phận như củ, hạt, lông, vỏ thân và vỏ rễ được sử dụng tương đối thấp. Trong 209 loài cây thuốc đã được thống kê, có nhiều loài được sử dụng đồng thời các bộ phận khác nhau làm thuốc.

\section{Mô hình bảo tồn}

Trên cơ sở những khảo sát tại khu vực nghiên cứu chúng tôi tiến hành nghiên cứu và đưa ra mô hình bảo tồn sau đây:

Bảo tồn nguyên vị: Khoanh nuôi tự nhiên trên diện tích $500 \mathrm{~m}^{2}$, với số lượng 1000 cây các loài như Hoa tiên, Hà thủ ô đỏ, Râu hùm, Thiên niên kiện, Giảo cổ lam, Bách bộ, Củ bình vôi, Dây đau xương, Nghệ đen, Nghệ vàng... dưới tán rừng tại khu vực vườn rừng tại Thác Mơ, xã Sơn Phú, huyện Na Hang, tỉnh Tuyên Quang. Theo dõi sự sinh trưởng và phát triển của cây. Nhìn chung, tại khu vực khoanh nuôi và trồng mới, cây sinh trưởng và phát triển tốt.

Bảo tồn chuyển vị: Trồng dưới tán rừng trong khu vực vườn rừng của một số hộ tại Bản Bung ở độ cao 200 - 430 m, diện tích 150 m²/hộ với số lượng 100 cây con/loài đã nhân giống. Cây có đủ độ che sáng và độ ẩm, được chăm sóc tốt nên sinh trưởng và phát triển cũng khá, tỷ lệ cây sống khá cao đạt $50,41 \%$.

\section{Kết luận}

Rừng đặc dụng Na Hang, tỉnh Tuyên Quang có nguồn tài nguyên cây thuốc đa dạng, hiện đã biết có 275 loài cây thuốc, thuộc 96 họ, 204 chi của 4 ngành thực vật bậc cao có mạch; trong đó, số lượng cây thuốc mà đồng bào người dân tộc Cao Lan sử dụng có 209 loài, thuộc 85 họ, 168 chi của 03 ngành thực vật bậc cao có mạch. Trong số 204 loài, có 05 loài được ghi trong Sách Đỏ Việt Nam, Danh lục Đỏ cây thuốc Việt Nam.

Trong số 85 họ, có 11 họ có số loài nhiều nhất là họ Cà phê - Rubiaceae, Thầu dầu Euphorbiaceae, Gừng - Zingberaceae, Ráy - Araceae, họ Nho - Vitaceae, Ô rô - Acanthaceae, Cỏ roi ngựa - Verbenaceae, Cơm nguội - Myrsinaceae, Dâu tằm - Moraceae, Tiết dê - Menispermaceae và Mạch môn đông - Convallariaceae.

Trong số 168 chi, có 4 chi có số lượng loài được sử dụng làm thuốc nhiều nhất là chi Piper, Ficus, Elastostema và Clerodendrum.

Dạng sống chủ yếu của các loài cây thuốc được người dân tộc Cao Lan sử dụng chủ yếu là cây thân thảo $(41,63 \%)$ và cây bụi $(22,01 \%)$; cây thân gỗ và cây thân leo được sử dụng ít hơn (16,75\% và $17,70 \%)$; còn lại là cây bì sinh và cây kí sinh chiếm tỷ lệ rất thấp.

Các bộ phận được sử dụng nhiều nhất là thân, lá, rễ và toàn cây; còn lại là các bộ phận như củ, hạt, lông, vỏ thân và vỏ rễ được sử dụng tương đối thấp.

\section{Lời cảm ơn:}

Các kết quả nghiên cứu này được hỗ trợ bởi kinh phí thực hiện từ nguồn sự nghiệp khoa học của tỉnh Tuyên Quang cho đề tài cấp tỉnh: "Điều tra, đánh giá hiện trạng nguồn tài nguyên cây thuốc tại một số xã vùng cao của huyện Na Hang, đề xuất giải pháp bảo tồn và sử dụng bền vĩng một số loài có giá trị và triển vọng”. 


\section{TÀI LIỆU THAM KHẢO}

1. Nguyễn Tiến Bân (1997), Cẩm nang tra cưu và nhận biết các họ thực vật hạt kín ở Việt Nam, Nxb Nông nghiệp. Hà Nội.

2. Bộ Khoa học \& Công nghệ, Viện Khoa học và Công nghệ Việt Nam (2007), Sách Đỏ Việt Nam (Phần thực vật), Nxb Khoa học tự nhiên và Công nghệ, Hà Nội.

3. Chính phủ nước CHXHCN Việt Nam (2006), Nghị định 32/2006/NĐ-CP của Chính phủ về quản lý thực vật rù̀ng, động vật rùng nguy cấp, quý hiếm.

4. Võ Văn Chi (2003), Tù điển thục vật thông dụng, tập I, II, Nxb Khoa học và Kỹ thuật, Hà Nội.

5. Võ Văn Chi (1997), Tù điển cây thuốc Việt Nam, Nxb Y Học, Tp. Hồ Chí Minh.

6. Võ Văn Chi, Nguyễn Đức Minh (2000), Rắn làm thuốc và thuốc trị rắn cắn, Nxb. Khoa học và Kỹ thuật, Hà Nội.

7. Võ Văn Chi (2005), Cây rau, trái đậu dùng để ăn và trị bệnh, Nxb Khoa học và Kỹ thuật.

8. Phạm Hoàng Hộ (1999 - 2000), Cây cỏ Việt Nam, tập 1-3, Nxb Trẻ, Tp. Hồ Chí Minh.

9. Đỗ Tất Lợi (1999), Nhũng cây thuốc và vị thuốc Việt Nam, Nxb. Khoa học và Kỹ thuật, Hà Nội.

10. Trần Đình Lý (1995), 1900 loài cây có ích, Nxb Thế Giới, Hà Nội.

11. Nguyễn Tập (2006), "Danh lục Đỏ cây thuốc Việt Nam”, Tạp chí Dược liệu, 3(11): 97105.

12. Nguyễn Tập (2006), Cẩm nang cây thuốc cần bảo vệ ở Việt Nam. Mạng lưới Lâm sản ngoài gố Việt Nam.

13. Nguyễn Nghĩa Thìn (1999), Cẩm nang nghiên cứu Đa dạng sinh học, Nxb. Nông nghiệp, Hà Nội.

14. Nguyễn Nghĩa Thìn, Đặng Quyết Chiến (2006), Đa dạng thục vật Khu Bảo tồn thiên nhiên Na Hang, tỉnh Tuyên Quang, Nxb. Nông nghiệp, Hà Nội.

15. Viện Dược liệu (2006), Cây thuốc và động vật làm thuốc ở Việt Nam, tập I, II, Nxb. Khoa học và Kỹ thuật, Hà Nội. 